\title{
Job Strain
}

National Cancer Institute

\section{Source}

National Cancer Institute. Job Strain. NCI Thesaurus. Code C92619.

Negative physical or emotional health outcomes resulting from high job demands with low job decision latitude. 